\title{
Expression of estrogen-related receptors in ovarian cancer and impact on survival
}

\author{
Susanne Schüler-Toprak ${ }^{1}$ (1) $\cdot$ Florian Weber ${ }^{2} \cdot$ Maciej Skrzypczak $^{3}$ - Olaf Ortmann ${ }^{1} \cdot$ Oliver Treeck $^{1}$
}

Received: 29 January 2021 / Accepted: 24 May 2021 / Published online: 5 June 2021

(c) The Author(s) 2021

\begin{abstract}
Purpose This study further approaches the role of estrogen-related receptors (ERRs) in ovarian cancer. Protein expression of ERR $\alpha, E R R \beta$ and ERR $\gamma$ in ovarian cancer was assessed and was correlated with ovarian cancer markers, steroid hormone receptors and cancer-associated genes. Additionally, we examined to what extent expression of ERRs affects survival of ovarian cancer patients.

Methods For this purpose, we established a tissue microarray from 208 ovarian cancer patients and performed immunohistochemical analyses of the mentioned proteins.

Results ERR $\alpha$ and ERR $\gamma$ protein could be detected at different levels in more than $90 \%$ of all ovarian cancer tissues, whereas expression of ERR $\beta$ was observed in $82.2 \%$ of the cases. ERR $\alpha$ was found to positively correlate with ovarian cancer marker CEA $(p<0.005)$ and ERR $\gamma$ correlated with $\operatorname{ER} \alpha(p<0.001)$. Univariate survival analyses revealed that ERR $\alpha$ expression did not affect overall (OS) or progression-free survival (PFS) of ovarian cancer patients. In contrast, higher expression of ERR $\beta$ in serous ovarian cancers was found to lead to a significantly decreased OS $(p<0.05)$. The strongest impact on survival was exhibited by ERR $\gamma$. Lower expression of this receptor in women with serous ovarian cancers indicated significantly increased OS compared to those with higher levels of ERR $\gamma(p<0.05)$. Multivariate survival analyses revealed ERR $\gamma$ as an independent prognostic marker regarding OS of patients with serous ovarian cancer.

Conclusion Our data demonstrating that ERR proteins are frequently expressed in ovarian cancer and high levels of ERR $\beta$ and ERR $\gamma$ significantly decreased OS of serous ovarian cancer patients suggest that these proteins might be interesting therapy targets in this cancer entity.
\end{abstract}

Keywords Estrogen-related receptors · Ovarian cancer · Overall survival · Progression-free survival · Tissue microarray

Susanne Schüler-Toprak and Florian Weber both authors contributed equally.

Susanne Schüler-Toprak

Susanne.Schueler@klinik.uni-regensburg.de

Florian Weber

Florian.Weber@klinik.uni-regensburg.de

Maciej Skrzypczak

skrzypm@yahoo.co.uk

Olaf Ortmann

oortmann@klinik.uni-regensburg.de

Oliver Treeck

otreeck@caritasstjosef.de

\section{Introduction}

Ovarian cancer is the leading cause of death from a gynaecological malignancy in the developed world (Siegel et al. 2018). Due to missing screening methods and the aggressive behavior of the disease, the majority is diagnosed in

1 Department of Gynecology and Obstetrics, University Medical Center Regensburg, Landshuter Str. 65, 93053 Regensburg, Germany

2 Department of Pathology, University Medical Center Regensburg, Franz-Josef Strauß Allee11, 93053 Regensburg, Germany

3 Second Department of Gynecology, Medical University of Lublin, Jaczewskiego 8, 20-090 Lublin, Poland 
advanced stages (Torre et al. 2018). Ovarian cancer has been shown to be influenced by steroid hormones. Estrogens activate growth in ovarian cancer cells via ER $\alpha$ which is often overexpressed in this cancer entity (Chan et al. 2017; O'Donnell et al. 2005). In contrast, both expression and specific activation of ER $\beta$ which is downregulated in most ovarian cancer cases, reduces ovarian cancer cell proliferation (Halon et al. 2011; Schüler-Toprak et al. 2017; Treeck et al. 2007).

To date, knowledge on the function and expression of estrogen-related receptors (ERRs) $\alpha, \beta$ and $\gamma$ in ovarian cancer is sparse. Generally, ERRs are transcription regulators. They use estrogen response elements (EREs) and extended ERE half-sites termed ERR response elements (ERREs) (Ariazi and Jordan 2006). However, endogenous estrogens are no ligands of these orphan receptors (Ariazi and Jordan 2006). ERRs interact with ER $\alpha$ and several other nuclear receptors (Tanida et al. 2015; Yamamoto et al. 2012). Thereby, among others, a vast number of different genes modulating metabolic processes are regulated and several different pathways are controlled (Ranhotra 2012).

ERR $\alpha$ which has attracted the greatest attention to date, acts as a master regulator of cellular metabolism, thereby also promoting tumor growth (Liu et al. 2018). ERR $\alpha$ modulates estrogen responsiveness and substitutes for ER activities in breast cancer and was found to be critical for growth of ER $\alpha$-negative breast cancer cells (Kraus et al. 2002; Liu et al. 2018; Stein and McDonnell 2006). It increases breast cancer cell migration, proliferation, and tumor development, activates estrogen-responsive genes in endocrine-resistant tumors and associates with unfavorable biomarkers in breast cancer, suggesting ERR $\alpha$ as novel target for therapy of breast cancer (Ariazi et al. 2002; May 2014). With regard to ovarian cancer, a very limited number of studies exist, reporting that targeted inhibition of ERR $\alpha$ hindered epithelial-tomesenchymal transition and stem cell properties of ovarian cancer cells (Lam et al. 2014). A small study including 33 ovarian cancer patients suggested a reduced overall survival (OS) of patients with high ERR $\alpha$ levels (Sun et al. 2005). In an mRNA-based study, the levels of ERR $\alpha$ transcripts increased with clinical stages in ovarian cancers (Fujimoto et al. 2007).

ERR $\beta$ suppresses growth of prostate cancer cells via p21(WAF1) induction making it a potential therapeutic target in prostate cancer (Yu et al. 2008). In breast cancer, $\mathrm{ERR} \beta$ is upregulated by estrogens in an ER $\alpha$-dependent manner and inversely correlated with OS of breast cancer patients (Madhu Krishna et al. 2018). With regard to ovarian cancer, few data have been published on this receptor. A study on the mRNA-level stated that ERR $\beta$ levels in ovarian cancer tissue were too low to determine reliably (Fujimoto et al. 2007). Thus, further studies on ERR $\beta$ in ovarian cancer are necessary.
ERR $\gamma$ binds Bisphenol A (Tohmé et al. 2014) and affects estrogen responsiveness in endometrial cancer cells (Yamamoto et al. 2012). It correlates with favorable markers in breast cancer (Ariazi et al. 2002). With regard to ovarian cancer, again only limited studies exist. The small study mentioned above including 33 patients suggested that high expression of this receptor is associated with a longer progression-free survival (PFS) (Sun et al. 2005).

Given that there are only few data on the significance of ERR protein levels in ovarian cancer, in this study, we examined protein expression of ERR $\alpha, \beta$ and $\gamma$ in 208 ovarian cancer samples, performed correlation analyses with ovarian cancer markers, steroid hormone receptors and other cancer-associated genes and finally performed Kaplan-Meier analyses to elucidate the effect of their expression levels on survival of ovarian cancer patients.

\section{Materials and methods}

\section{Tissue samples}

We included ovarian cancer samples collected in the Department of Pathology of the University of Regensburg. Generally, Caucasian women with sporadic ovarian cancer and available information on grading, stage, and histological subtype from 1995 to 2013 were included. Patients' clinical data were available from tumor registry database information provided by the Tumor Center Regensburg (Bavaria, Germany). This high-quality population-based regional cancer registry was founded in 1991 and covers a population of more than 2.2 million people of Upper Palatinate and Lower Bavaria. Information about diagnosis, course of disease, therapies, and long-term follow-up are documented. Patient data originate from the University Hospital Regensburg, 53 regional hospitals, and more than 1000 practicing doctors in the region. Based on medical reports, pathology, and followup records, these population-based data are routinely being documented and fed into the cancer registry. The retrospective study was approved by the institutional review board "Ethics Committee University of Regensburg".

\section{Tissue microarray and immunohistochemistry}

The tissue microarray (TMA) was created using standard procedures that have been previously described (Mirlacher and Simon 2010). From all patients included in this study, an experienced pathologist evaluated $\mathrm{H} \& \mathrm{E}$ sections of tumor tissue and representative areas were marked. From these areas, core biopsies on the corresponding paraffin blocks were removed and transferred into the grid of a recipient block according to a predesigned array of about 60 specimens in each of five TMA paraffin blocks. 
For immunohistochemistry, $4 \mu \mathrm{m}$ sections of the TMA blocks were incubated with the indicated antibodies according to the mentioned protocols in the given dilutions (Supplemental table S1), followed by incubation with an HRPconjugated secondary antibody and another incubation with 3,3'-diaminobenzidine (DAB) as substrate, which resulted in a brown-colored precipitate at the antigen site. An experienced clinical pathologist evaluated immunohistochemical staining according to localization and specificity (Fig. 1). For determination of staining intensity of ERR $\alpha$ and ERR $\gamma$, a score from 0 (negative) to 3 (strongly positive) was used. Since staining intensities for ERR $\beta$ were generally lower, a score from 0 to 2 was used. For steroid hormone receptors ER $\alpha$, nuclear ER $\beta$ and PR, the immunoreactivity score according to Remmele et al. was used (Remmele and Stegner 1987). Expression of proliferation marker Ki-67 using antibody clone MIB-1 was assessed in the percentage of tumor cells with positive nuclear staining. Her2/neu expression was scored according to the DAKO score routinely used for breast cancer cases. EGFR was scored according to Spaulding et al. on a 4-tiered scale from 0 to 3 (Spaulding and Spaulding 2002). For p53 and polyclonal CEA, the "quickscore" was used, where results are scored by multiplying the percentage of positive cells $(P)$ by the intensity (I) according to the formula: $Q=P \times I$; maximum $=300$ (Charafe-Jauffret et al. 2004). CA-125 and ER $\beta$ were described as positive or negative, irrespective of staining intensity.

\section{Statistical analysis}

Apart from multivariate survival analyses, statistical analysis was performed using GraphPad Prism $5^{\circledR}$ (GraphPad Software, Inc., La Jolla, CA, USA). The non-parametric Kruskal-Wallis rank-sum test was used for testing differences in receptor expression among three or more groups. For pairwise comparison the non-parametric Mann-Whitney U rank-sum test was used. Correlation analysis was performed using the Spearman correlation coefficient. Univariate survival analyses were performed using the Kaplan-Meier method. The chi-squared statistic of the log-rank was used to investigate differences between survival curves. Hazard ratios were calculated using the Mantel-Haenszel method. P values below 0.05 were considered statistically significant. Multivariate Cox regression survival analysis was performed using IBM $^{\circledR}$ SPSS $^{\circledR}$ Statistics 25 (SPSS $^{\circledR}$, IBM ${ }^{\circledR}$ Corp., Armonk, NY, USA) using the Enter method.

\section{Results}

\section{Characteristics of included patients and their tumors}

Tissues from 208 Caucasian women with sporadic ovarian cancer were used in this study. Median age at diagnosis was 63.5 years (29-91 years). Table 1 shows the histopathological characteristics. Serous ovarian cancers represent $64.9 \%$ of the tumors and $58.8 \%$ were grade 3 . Most of the cancers were diagnosed in FIGO (International Federation of Gynecologists and Obstetricians) stages III and IV (31.25\% and $24.04 \%$, respectively). During the median follow-up of 1180 days, 80 relapses and 62 deaths were documented. While median relapse-free survival was 1044 days, median overall survival (OS) was 1079 days.

\section{Comparison of ERR expression in ovarian cancer and normal ovary using publicly available mRNA data}

Given that we could not collect a sufficient amount of normal ovarian tissues, we decided to use the benefits of publicly available gene expression data and were thereby able to compare ERR mRNA expression in 426 ovarian cancer tissues and 88 normal ovarian tissues. This analysis of open source TCGA and GTEx mRNA data using the GEPIA online tool (http://gepia.cancer-pku.cn) revealed a notable overexpression of ERR $\alpha, \beta$ and $\gamma$ mRNA in ovarian cancer tissue (Fig. 2).

\section{Expression of estrogen-related receptors in ovarian cancer tissue}

We demonstrate ERRs to be widely expressed in most ovarian cancer tissues as assessed on the protein level by means of immunohistochemistry of tissue microarrays (TMAs). Positive staining of ERR $\alpha$ was found in $91.8 \%$ of all cases (39.4\% weak staining, $45.7 \%$ moderate and $6.7 \%$ strong staining). ERR $\beta$ was detected in $82.2 \%$ of all tumors, among them $68.8 \%$ with clearly positive but weaker staining, the further samples exhibited stronger staining for this receptor. ERR $\gamma$ was expressed in $96.6 \%$ of all ovarian cancer samples (10.1\% with weaker staining, $50.9 \%$ with moderate and $35.6 \%$ with strong staining (Table 2a). Only considering the largest subgroup of serous ovarian cancer, we detected similar frequencies. Thus, overall staining intensities were highest for ERR $\gamma$, followed by ERR $\alpha$ and lowest for ERR $\beta$ both in all ovarian cancer samples and in the serous subgroup. With regard to ERR $\gamma$, we observed a statistically significant higher mean staining intensity (2.28) in tumors 

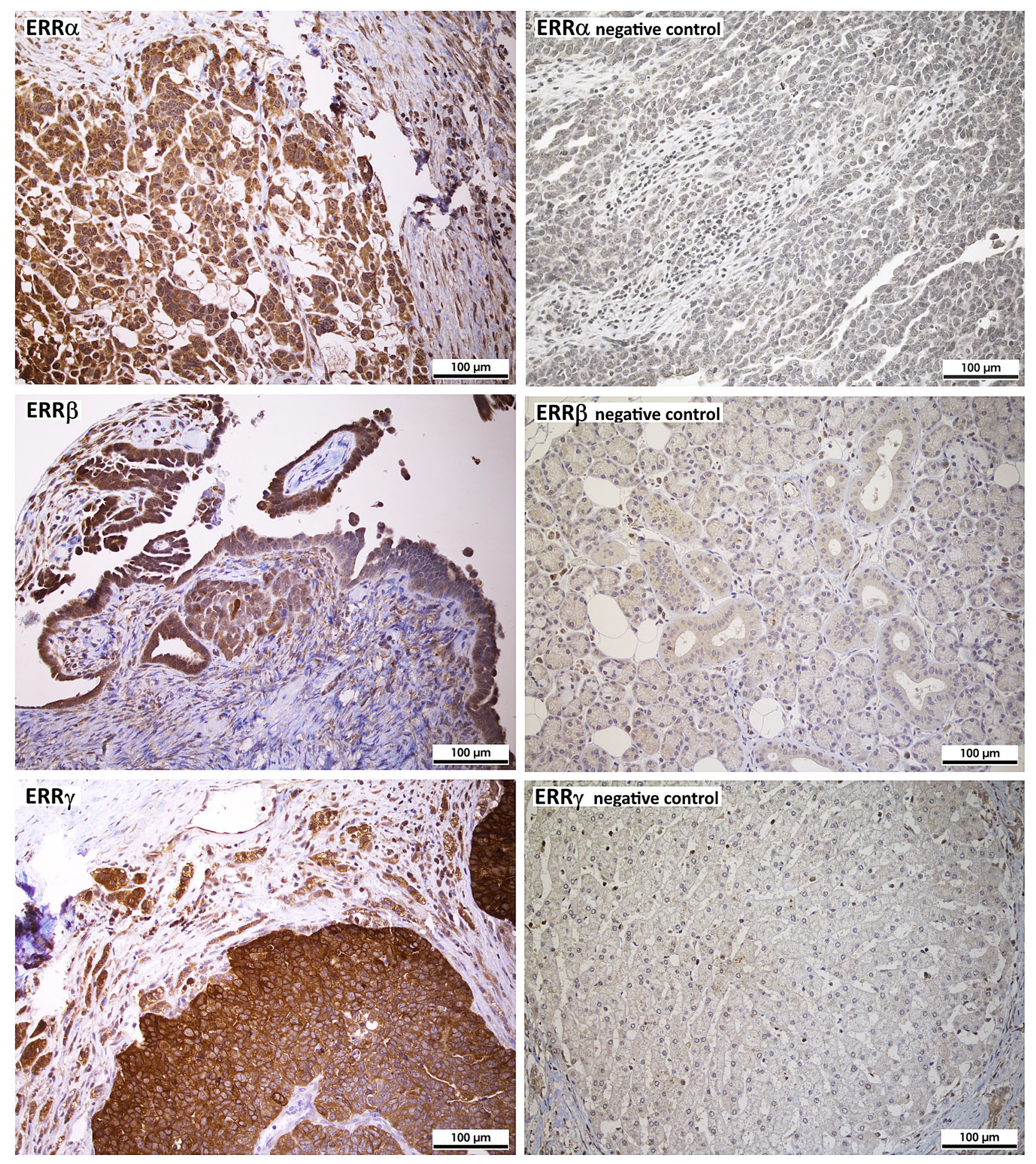

Fig. 1 Analysis of protein expression of the indicated ERRs in ovarian cancer tissue microarrays (TMAs) by immunohistochemistry ( $200 \times$ magnification). On the left side, three representative examples of positive staining of the indicated receptors in serous high-grade ovarian cancer tissue (G3) is shown. On the right side, examples

for negative staining are shown (top: negative ovarian cancer tissue, middle: salivary gland, bottom: liver). The absence of ERR $\beta$ and $\gamma$ expression in these tissues is confirmed by data of www.proteinatlas. org 
Table 1 Stages and histopathological characteristics of the included ovarian cancer cases

\begin{tabular}{lrr}
\hline Characteristics & Number of patients & $(\%)$ \\
\hline Ovarian cancer patients & 208 & \\
FIGO stage & & \\
FIGO I & 22 & 10.58 \\
FIGO II & 8 & 3.85 \\
FIGO III & 65 & 31.25 \\
FIGO IV & 50 & 24.04 \\
Unknown & 63 & 30.29 \\
Histological subtype & & \\
Serous & 135 & 64.90 \\
Mucinous & 6 & 2.88 \\
Endometrioid & 10 & 4.81 \\
Clear cell & 3 & 1.44 \\
Undifferentiated & 54 & 25.96 \\
Histological grade & & \\
G2 & 53 & 25.48 \\
G3 & 122 & 58.65 \\
Unknown & 33 & 15.87 \\
\hline
\end{tabular}

with FIGO stages III or IV than in those staged I or II (1.88) ( $p=0.004$ ) (Fig. 3). Including serous ovarian cancers only, we also observed an increased mean staining intensity of ERR $\gamma$ in FIGO stages III and IV (2.27) than in FIGO staged I or II tumors (1.93) $(p=0.47)$ (Table 2b). In contrast, we did not observe any significant difference in expression levels of any ERR between G2 and G3 graded tumors or with patients with different nodal status. Moreover, invasion of lymph vessels or the venous system did not depend on expression of any ERR. ERR expression in metastases also did not significantly differ from their levels in primary tumors (data not shown).

\section{Correlation of ERR expression with steroid hormone receptors, ovarian cancer markers and other cancer-related genes}

To further analyse the role of ERRs in ovarian cancer, we examined correlations between the expression levels of $\mathrm{ERR} \alpha, \beta$ and $\gamma$ with levels of $\mathrm{ER} \alpha, \mathrm{ER} \beta, \mathrm{PR}, \mathrm{CA} 125, \mathrm{CEA}$, CA72-4, EGFR, HER2, Ki-67 and p53 in all ovarian cancer tissues. By means of Spearman's rank correlation analysis, we observed a positive association between all ERRs. $\mathrm{ERR} \alpha$ correlated with $\operatorname{ERR} \beta(\mathrm{rho}=0.4785, p<0.0001)$ and with $\operatorname{ERR} \gamma($ rho $=0.3504, p<0.0001)$, whereas $\operatorname{ERR} \beta$ was also associated with expression of ERR $\gamma(\mathrm{rho}=0.4317$, $p<0.0001$ ) (Table 3). Furthermore, we observed a positive association of ERR $\alpha$ with cancer marker CEA ( rho $=0.254$, $p<0.005) . \mathrm{ERR} \gamma$ was associated with expression of ER $\alpha$ (rho $=0.2858, p<0.001$ ). Expression of the other proteins mentioned above was not significantly associated with any ERR.
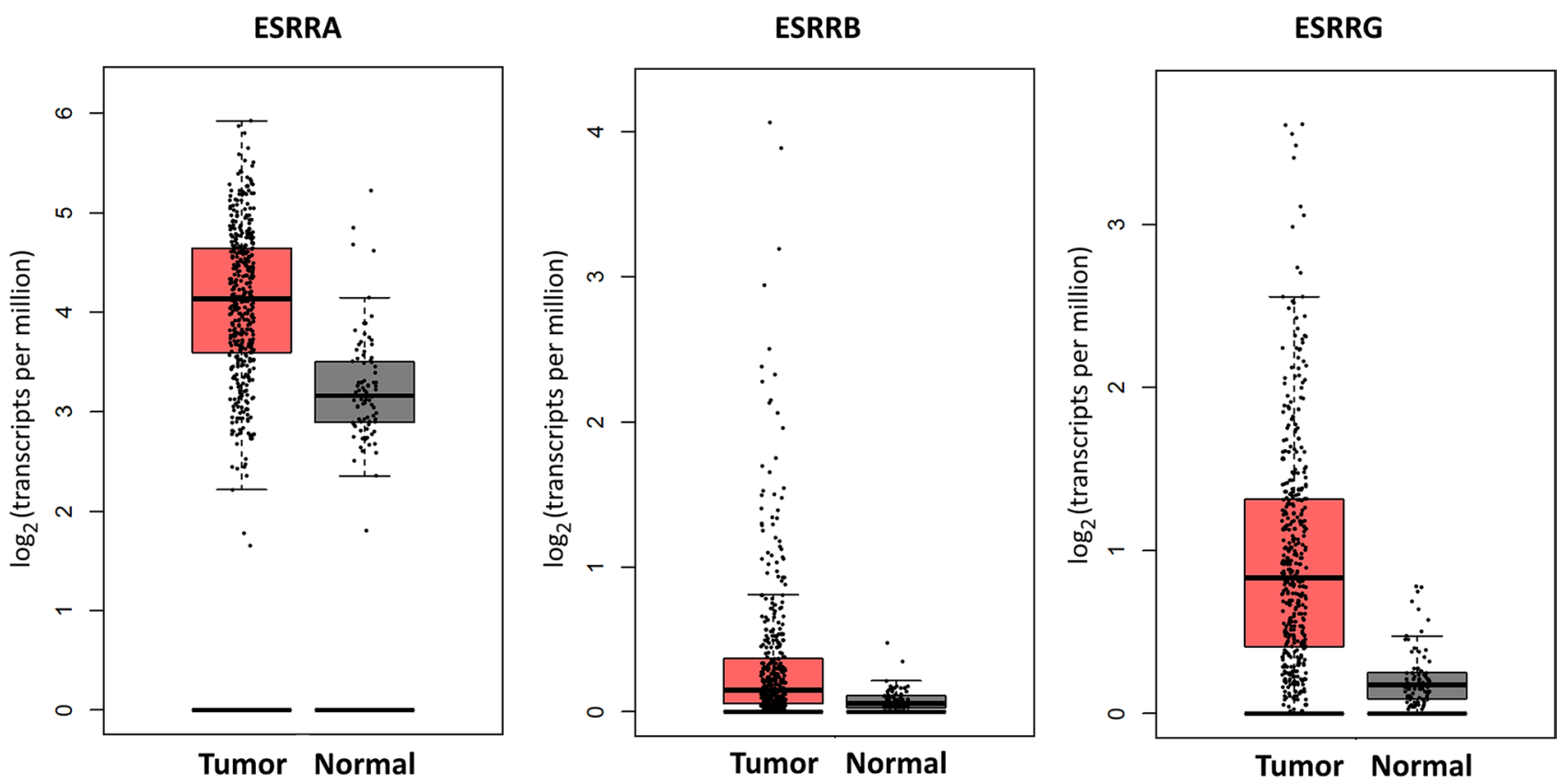

Fig. 2 Comparison of ERR mRNA levels in ovarian cancer and normal ovarian tissue based on open source TCGA and GTEx mRNA data using the GEPIA online tool (http://gepia.cancer-pku.cn). Indicated are the ERR genes ESRRA, coding for ERR $\alpha$ protein and
ESRRB and ESRRG, coding for the receptors ERR $\beta$ and ERR $\gamma$, respectively. Compared is the expression in 426 ovarian cancer tissues and 88 normal ovarian tissues 
Table 2 Expression of estrogen-related receptors (ERRs) in ovarian cancer

a) Rate of expression of the indicated receptors. Shown are the numbers of positive samples in relation to the total numbers of ovarian cancer cases $(n=208)$ or of the subgroups analyzed and the corresponding percent value (in brackets)

\begin{tabular}{|c|c|c|c|c|}
\hline & & $\mathrm{ERR} \alpha$ & $\operatorname{ERR} \beta$ & $\mathrm{ERR} \gamma$ \\
\hline \multirow[t]{5}{*}{ All } & All & $191 / 208(91.8 \%)$ & $171 / 208(82.2 \%)$ & $201 / 208(96.6 \%)$ \\
\hline & G2 & $52 / 53(98.1 \%)$ & $35 / 53(66.0 \%)$ & $52 / 53(98.1 \%)$ \\
\hline & G3 & $114 / 122(93.4 \%)$ & $115 / 122(94.2 \%)$ & $119 / 122(97.5 \%)$ \\
\hline & FIGO I+ II & $30 / 30(100 \%)$ & $21 / 30(70.0 \%)$ & $27 / 30(90.0 \%)$ \\
\hline & FIGO III + IV & $107 / 115(93.0 \%)$ & $103 / 115(89.6 \%)$ & $115 / 115(100 \%)$ \\
\hline \multirow[t]{5}{*}{ Serous } & Serous & $128 / 135(94.8 \%)$ & $117 / 135(86.7 \%)$ & $132 / 135(97.8 \%)$ \\
\hline & G2 & $23 / 23(100 \%)$ & $16 / 23(69.6 \%)$ & $23 / 23(100 \%)$ \\
\hline & G3 & 90/97 (92.7\%) & $86 / 97(88.7 \%)$ & 95/97 (97.9\%) \\
\hline & FIGO I+ II & $16 / 16(100 \%)$ & $13 / 16(81.2 \%)$ & $16 / 16(100 \%)$ \\
\hline & FIGO III + IV & $77 / 84(91.7 \%)$ & $72 / 84(85.7 \%)$ & $82 / 84(97.6 \%)$ \\
\hline
\end{tabular}

(b) Mean receptor expression levels in all ovarian cancer specimens and in the serous subgroup. A non-parametric Kruskal-Wallis rank-sum test was used for testing differences in receptor expression of the indicated ERRs among the groups. $P$ values $<0.05$ were considered statistically significant (indicated using bold font)

\begin{tabular}{|c|c|c|c|c|c|c|c|}
\hline & & \multicolumn{2}{|l|}{$\mathrm{ERR} \alpha$} & \multicolumn{2}{|l|}{$\mathrm{ERR} \beta$} & \multicolumn{2}{|l|}{$\mathrm{ERR} \gamma$} \\
\hline & & Mean & $p$ value & Mean & $p$ value & Mean & $p$ value \\
\hline \multirow[t]{4}{*}{ All } & G2 & 1.552 & 0.699 & 0.923 & 0.428 & 2.230 & 0.987 \\
\hline & G3 & 1.611 & & 1.056 & & 2.314 & \\
\hline & FIGO I+ II & 1.461 & 0.438 & 0.846 & 0.101 & 1.884 & 0.004 \\
\hline & FIGO III + IV & 1.580 & & 1.035 & & 2.277 & \\
\hline \multirow[t]{4}{*}{ Serous } & G2 & 1.606 & 0.776 & 0.909 & 0.549 & 2.347 & 0.284 \\
\hline & G3 & 1.562 & & 0.987 & & 2.183 & \\
\hline & FIGO I+ II & 1.466 & 0.648 & 0.866 & 0.487 & 1.933 & 0.047 \\
\hline & FIGO III + IV & 1.558 & & 0.971 & & 2.271 & \\
\hline
\end{tabular}

Fig. 3 ERR protein expression levels in different FIGO groups as assessed after IHC detection of the indicated proteins on tissue microarrays (TMAs) with 208 ovarian cancer samples. Shown is the mean value of expression scores

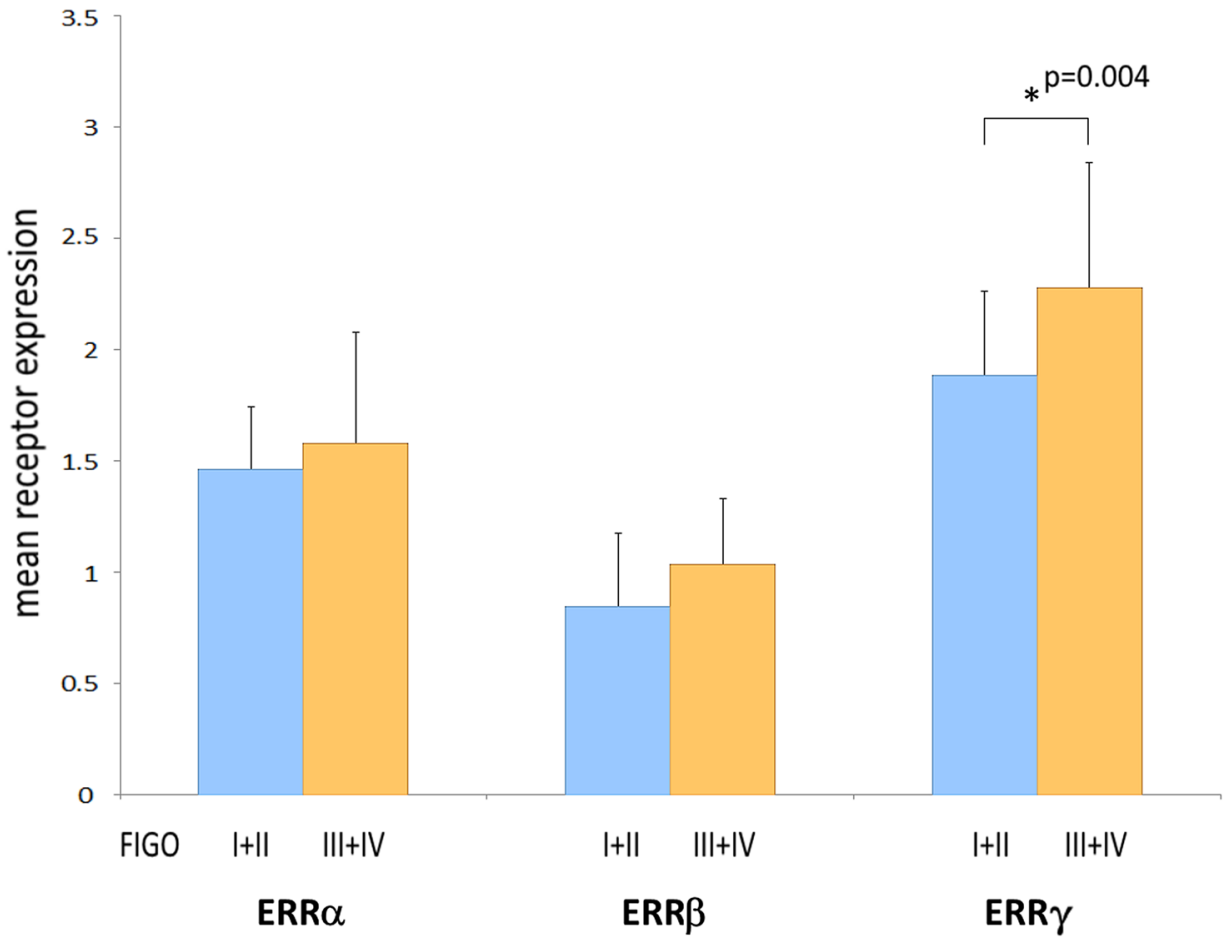


Table 3 Association of ERR $\alpha$, $\beta$ and $\gamma$ with the indicated steroid hormone receptors and cancer-associated genes in ovarian cancer tissues assessed by means of Spearman's rank correlation analysis

\begin{tabular}{|c|c|c|c|}
\hline & $E R R \alpha$ & ERR $\beta$ & $\mathrm{ERR} \gamma$ \\
\hline $\mathrm{ERR} \alpha$ & & $\begin{array}{l}\text { rho }=0.4785 \\
95 \% \text { CI } 0.3457-0.5926 \\
p<0.0001\end{array}$ & $\begin{array}{l}\text { rho }=0.3504 \\
95 \% \text { CI } 0.203-0.4823 \\
p<0.0001\end{array}$ \\
\hline ERR $\beta$ & $\begin{array}{l}\text { rho }=0.4785 \\
95 \% \text { CI: } 0.3457-0.5926 \\
p<0.0001\end{array}$ & & $\begin{array}{l}\text { rho }=0.4317 \\
95 \% \text { CI } 0.2944-0.5515 \\
p<0.0001\end{array}$ \\
\hline $\mathrm{ERR} \gamma$ & $\begin{array}{l}\text { rho }=0.3504 \\
95 \% \text { CI } 0.203-0.4823 \\
p<0.0001\end{array}$ & $\begin{array}{l}\text { rho }=0.4317 \\
95 \% \text { CI } 0.2944-0.5515 \\
p<0.0001\end{array}$ & \\
\hline $\mathrm{ER} \alpha$ & n.s & n.s & $\begin{array}{l}\text { rho }=0.2858 \\
95 \% \text { CI } 0.1346-0.424 \\
p<0.001\end{array}$ \\
\hline CEA & $\begin{array}{l}\text { rho }=0.254 \\
95 \% \text { CI } 0.09935-0.3967 \\
p<0.005\end{array}$ & n.s & n.s \\
\hline
\end{tabular}

Shown are the rank correlation coefficient (rho), the $95 \%$ confidence interval (CI) and the $p$-value, considered as statistically significant in case of $p<0.005$ (due to multiple comparison analysis)

Correlations with ER $\beta$, PR, MKI67, TP53, HER2, EGFR, CA-125 and CA72-4 were also tested, but were not statistically significant

\section{Analysis of ERR expression in ovarian cancer subgroups defined by the level of molecular marker expression}

Next, we compared the mean protein levels of ERR $\alpha$, $\beta$ and $\gamma$ in ovarian cancer subgroups with high vs. low expression of the molecular markers examined in this study, like steroid hormone receptors, ovarian cancer markers and proliferation markers. First, we found that mean levels of ERR $\alpha$ and ERR $\gamma$ were elevated in ovarian cancer specimen with higher ER $\alpha$ expression when compared to the lower expressing subgroup $(p=0.02$ or $p=0.001$, respectively) (Table 4 ). Mean protein levels of ERR $\alpha, \beta$ and $\gamma$ were increased in ovarian cancers with higher expression of $\operatorname{ER} \beta$ ( $p=0.03, p=0.006$ and $p=0.003$, respectively). Protein levels of ERR $\alpha$ were also elevated in the CEA-high subgroup $(p=0.004)$. In the subgroup with higher expression of CA125, we observed increased ERR $\gamma$ levels $(p=0.011)$. In ovarian cancers with higher expression of proliferation marker Ki-67, we found a decreased mean $\operatorname{ERR} \alpha$ level $(p=0.03)$. ERR $\gamma$ protein levels were observed to be elevated in tumors with higher expression of tumor suppressor TP53 $(p=0.0007)$. Finally, mean protein expression of ERR $\alpha, \beta$ and $\gamma$ was elevated in ovarian cancers with higher expression of HER 2 receptor tyrosine kinase $(p=0.002, p=0.007$ and $p=0.013$, respectively). No differences in ERR expression levels could be observed between tumor subgroups with different levels of PR, CA72-4 or EGFR.

\section{Survival analyses}

\section{ERRa expression is not associated with overall or progression-free survival of ovarian cancer patients}

When we compared overall survival (OS) of all women with ovarian cancers expressing different levels of ERR $\alpha$ by means of Kaplan-Meier analysis, no significant differences were found (data not shown). We further investigated survival of patients with serous ovarian cancers. However, ERR $\alpha$ expression did not influence OS of these patients in our cohort (data not shown). The levels of this receptor also did not correlate with progression-free survival (PFS), neither when including all ovarian cancer cases, nor when analyzing only serous ovarian cancers.

\section{High expression of ERR $\beta$ protein in serous ovarian cancer is associated with a significantly decreased overall survival}

Survival analyses revealed a significantly increased OS of patients with serous ovarian cancers expressing no or low levels of ERR $\beta$ compared to those with serous tumors showing higher ERR $\beta$ expression (chi-squared statistic of the log-rank, $p=0.038$ ). Median survival of patients with serous ovarian cancers expressing high levels of ERR $\beta$ was 1058 days, whereas women with tumors with low expression of ERR $\beta$ had a median survival of 1938 days (hazard ratio (HR) 2.74; 95\% CI 1.06-7.11) (Fig. 4a). However, ERR $\beta$ levels did not affect PFS of these patients with serous ovarian 
Table 4 Mean protein levels of ERR $\alpha, \beta$ and $\gamma$ in ovarian cancer subject to high and low expression of the indicated genes

\begin{tabular}{|c|c|c|c|c|}
\hline & & ERR $\alpha$ & ERR $\beta$ & ERR $\gamma$ \\
\hline \multirow{2}{*}{$\mathrm{ER} \alpha$} & low & 1.52 & 0.93 & 2.06 \\
\hline & high & 1.75 & 1.11 & 2.53 \\
\hline & & $p=0.02$ & n.s. & $p=0.001$ \\
\hline \multirow{2}{*}{$E R \beta$} & low & 1.52 & 0.89 & 2.13 \\
\hline & high & 1.72 & 1.17 & 2.31 \\
\hline \multirow{3}{*}{ PR } & & $p=0.03$ & $p=0.0006$ & $p=0.03$ \\
\hline & low & 1.59 & 0.98 & 2.15 \\
\hline & high & 1.72 & 1.11 & 2.34 \\
\hline \multirow{3}{*}{ CEA } & & n.s. & n.s. & n.s. \\
\hline & low & 1.51 & 0.99 & 2.18 \\
\hline & high & 1.81 & 1.06 & 2.19 \\
\hline \multirow{3}{*}{ CA125 } & & $p=0.004$ & n.s. & n.s. \\
\hline & low & 1.42 & 1 & 1.91 \\
\hline & high & 1.65 & 1.03 & 2.25 \\
\hline \multirow{3}{*}{ CA72.4 } & & n.s. & n.s. & $p=0.011$ \\
\hline & low & 1.60 & 1.03 & 2.22 \\
\hline & high & 1.69 & 1.07 & 2.21 \\
\hline \multirow{3}{*}{ Ki-67 } & & n.s. & n.s. & n.s. \\
\hline & low & 1.69 & 1.01 & 2.14 \\
\hline & high & 1.49 & 1.00 & 2.28 \\
\hline \multirow{3}{*}{ TP53 } & & $p=0.03$ & n.s. & n.s. \\
\hline & low & 1.59 & 0.9 & 2.05 \\
\hline & high & 1.68 & 1.16 & 2.40 \\
\hline \multirow[b]{3}{*}{ HER2 } & & n.s. & n.s. & $p=0.0007$ \\
\hline & low & 1.35 & 0.79 & 1.97 \\
\hline & high & 1.80 & 1.09 & 2.30 \\
\hline \multirow{4}{*}{ EGFR } & & $p=0.002$ & $p=0.007$ & $p=0.013$ \\
\hline & low & 1.55 & 0.97 & 2.15 \\
\hline & high & 1.72 & 1.12 & 2.29 \\
\hline & & n.s. & n.s. & n.s. \\
\hline
\end{tabular}

Statistical significance was stated in the case of $p<0.05$ and was highlighted by light gray color

a

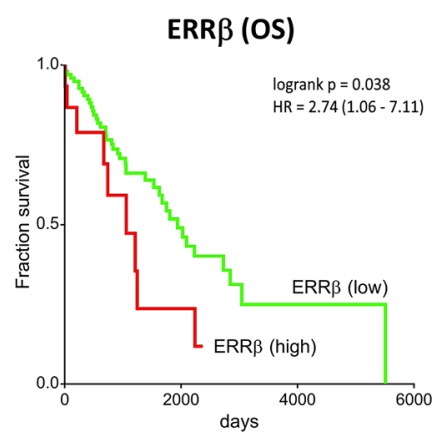

b

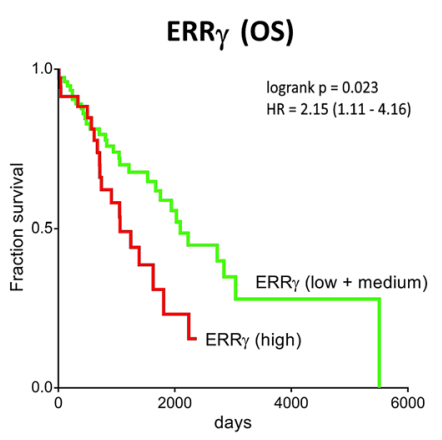

$\operatorname{ERR} \gamma$ (PFS)

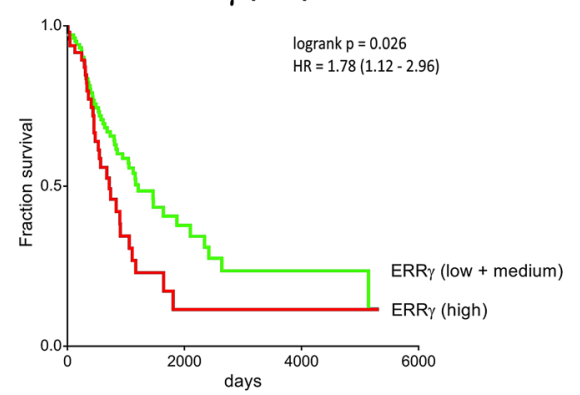

Fig. 4 Kaplan-Meier diagrams for survival analyses in relation to ERR protein expression. a Overall survival (OS) of patients with serous ovarian cancers with regard to expression to ERR $\beta$. b OS and progression-free survival (PFS) of ovarian cancer patients with different tumoral expression of ERR $\gamma$; shown is the OS of serous ovarian cancer patients with low and medium expression of ERR $\gamma$ compared to those expressing high levels of ERR $\gamma$ and the PFS of all ovarian cancer patients with low and medium expression of ERR $\gamma$ compared to those expressing high levels of ERR $\gamma$. The hazard ratio (HR) is indicated with the $95 \%$ confidence interval in brackets 
cancer (data not shown). We did not observe significant differences in OS or PFS depending on ERR $\beta$ expression when analyzing all histologic subtypes (data not shown).

\section{ERRY protein expression levels are associated with OS in patients with serous ovarian cancers as well as with PFS of all patients with ovarian cancer}

High expression of ERR $\gamma$ in women with serous ovarian cancers indicated significantly increased OS compared to those with serous tumors expressing low or medium levels of ERR $\gamma$ (Chi-square statistic of the log-rank, $p=0.023$ ). Median survival of women with high ERR $\gamma$ expression was 1058 days compared to 2095 days of patients with serous cancers showing lower expression of ERR $\gamma$ (HR 2.15; 95\% CI 1.11-4.16) (Fig. 4b). We did not observe significant differences in OS depending on ERR $\gamma$ expression when analyzing all samples representing mixed histologic subtypes (data not shown). With regard to PFS, patients differed significantly when comparing all ovarian cancer cases with low and medium ERR $\gamma$ protein levels to those with high expression of ERR $\gamma$ (chi-squared statistic of the log-rank, $p=0.026$ ). Median PFS of women with ovarian cancers expressing low and medium levels of ERR $\gamma$ was 1213 days compared to 714 days of women suffering from tumors with high expression of ERR $\gamma$ (HR 1.78; 95\% CI 1.12-2.96) (Fig. 4b). Survival analyses of the subgroup of serous ovarian cancers revealed a trend toward longer PFS for ovarian cancer patients whose tumors showed low expression of ERR $\gamma$ compared to those with medium and high expression (data not shown).

\section{ERR $\gamma$ is an independent prognostic marker for OS in patients with serous ovarian cancer}

Multivariate Cox regression survival analysis was used to further investigate significant results of the beforehand performed univariate analyses. Thus, influence of protein expression levels of ERR $\beta$ and ERR $\gamma$ on OS of patients with serous ovarian cancer was examined. We found a significant effect of ERR $\gamma$ expression on OS of patients with serous ovarian cancer (HR 1.846; 95\% CI 1.097-3.108, $p=0.021$ ) making it an independent prognostic marker for OS in this subgroup of patients (Table 5). Protein expression of ERR $\beta$ did not have significant effects on OS in multivariate survival analysis (Table 5).

\section{Discussion}

Increasing evidence supports a clear influence of ERRs on carcinogenesis of different endocrine-regulated tumor entities making these receptors putative therapeutic targets.
Table 5 Multivariate survival analysis of overall survival (OS) of patients with serous ovarian cancer included protein expression of $\operatorname{ERR} \alpha$ and $\operatorname{ERR} \beta$

\begin{tabular}{llll}
\hline & HR & $p$ value & $95 \%$ CI \\
\hline ERR $\beta$ & 1.085 & 0.787 & $0.601-1.957$ \\
ERR $\gamma$ & $\mathbf{1 . 8 4 6}$ & $\mathbf{0 . 0 2 1}$ & $\mathbf{1 . 0 9 7 - 3 . 1 0 8}$ \\
\hline
\end{tabular}

Shown are the results of cox-regression analysis using the enter method (hazard ratio (HR) and 95\% confidence interval (CI). Statistical significance is stated in the case of $p<0.05$ and highlighted using bold font

Until now, little is known about the role of the ERR subtypes ERR $\alpha, \beta$ and $\gamma$ in ovarian cancers. We report protein expression of ERR $\alpha, \beta$ and $\gamma$ in the vast majority of 208 ovarian cancer samples as assessed by IHC of tissue microarrays (TMAs). Moreover, univariate survival analyses of our data suggest that high levels of ERR $\beta$ and ERR $\gamma$, but not ERR $\alpha$, significantly shorten the OS of patients with serous ovarian cancer. ERR $\gamma$ also negatively affected PFS of all ovarian cancer cases. Multivariate survival analysis points out ERR $\gamma$ as an independent prognostic marker for OS of patients with serous ovarian cancer.

When investigating the role of ERRs as a possible target in anticancer therapy of ovarian tumors, it is essential to learn more about their expression level and -frequency. Until now, little was known about protein expression of the different ERR subtypes in ovarian cancers. On the protein level, we detected ERR $\alpha$ in $91.8 \%, E R R \beta$ in $82.2 \%$ and ERR $\gamma$ in $96.6 \%$ of all tumors. Previous publications, including a small number of ovarian cancer cases, only investigated ERR expression on the mRNA level. Sun et al. detected mRNA of ERR $\alpha$ in their small study including 33 ovarian cancer cases in 19 of 33 samples (57.6\%) (Sun et al. 2005). Only three $(9.1 \%)$ ovarian cancer samples expressed the ERR $\beta$ mRNA. Expression of ERR $\gamma$ mRNA was observed in 16 of 33 ovarian cancers (48.5\%) (Sun et al. 2005). Fujimoto et al. also only found low mRNA expression levels of ERR $\beta$ and ERR $\gamma$ which made further analyses impossible (Fujimoto et al. 2007). When we analyzed open source TCGA and GTEx mRNA data for expression differences of the three ERRs between ovarian cancer and normal ovarian tissue, we found an overexpression of ERR $\alpha, \beta$ and $\gamma$ mRNA in ovarian cancer tissue compared to that of normal ovaries. This is in line with data published by Sun et al. (Sun et al. 2005). Heterogeneity of ovarian cancers often limits therapeutic effects. The high frequency of ERR protein expression in ovarian cancer we observed in our study might make these receptors attractive therapy targets.

Among the ERRs, the ERR $\alpha$ subtype attracted the greatest attention to date. In our IHC-based TMA study, ERR $\alpha$ protein expression levels did not affect OS or PFS of the included ovarian cancer patients. In breast, endometrial and 
ovarian cancer ERR $\alpha$ has been reported to act as a master regulator of cellular metabolism and to thereby also stimulate tumor growth (Liu et al. 2018). Moreover, ERR $\alpha$ was reported to promote cancer migration and metastasis in these endocrine-dependent gynaecological cancers (Liu et al. 2018). In in vitro studies, ERR $\alpha$ was suggested to exhibit pro-metastatic effects in ovarian cancer cells (Wang et al. 2017). In addition, ERR $\alpha$ was reported to activate Snail, a crucial regulator of epithelial-mesenchymal transition (EMT) (Lam et al. 2014). Inhibiting the expression of ERR $\alpha$ in vitro was shown to reduce the migratory capacity of breast, prostate and colon cancer cells, as well as ablation of $\beta$-catenin. Thus, the ERR $\alpha / \beta$-catenin/WNT11 signaling pathway was suggested to be biologically significant (Dwyer et al. 2010; Zhao et al. 2012). WNT11 has been found upregulated in several cancers and its expression has been previously associated with increased cell migration (Uysal-Onganer et al. 2010). Recent studies demonstrated that WNT11 expression is directly co-regulated with ERR $\alpha$ and $\beta$-catenin in several cancer cell lines, which is considered the key mechanism underlying the pro-migratory activity of ERR $\alpha$ (Dwyer et al. 2010; Zhao et al. 2012).

Here, we observed a positive correlation of ERR $\alpha$ protein expression with the ovarian cancer marker CEA. Carcinoembryonic antigen (CEA) is produced during fetal development and functions as a cellular adhesion factor during organ formation (Saeland et al. 2012). It is also involved in cellular adherence and aggregation processes (Abdul-Wahid et al. 2014). CEA acts as a paracrine factor, activating human fibroblasts by signaling through both STAT3- and AKT1mTORC1 pathways, promoting their transition to the cancerassociated fibroblast phenotype, and enhancing cell migration (Abdul-Wahid et al. 2018; Chen et al. 2019). Moreover, a connection between CEA and the WNT/ $\beta$-catenin oncogenic pathway has been reported (Chen et al. 2019). Thus, the observed positive correlation between ERR $\alpha$ and CEA expression might support the previously suggested oncogenic features of this receptor, as both trigger migratory and metastatic processes of cancer cells, among others via oncogenic WNT/ $\beta$-catenin signaling. In line with the previously suggested oncogenic role of ERR $\alpha$ we observed elevated expression levels of ERR $\alpha$ in ovarian cancers with high expression of $\mathrm{Ki}-67$ or HER2 in our cohort. This is also supported by our observation that transcript levels of ERR $\alpha$ are higher in ovarian cancers than in normal ovarian tissue, although ERR $\alpha$ expression did not affect survival in our patients' cohort.

With regard to ERR $\beta$, high protein expression of this orphan receptor in the subtype of serous ovarian cancers indicated a significantly shorter OS, suggesting an oncogenic effect of ERR $\beta$. Until now, data on the role of this orphan receptor in ovarian cancers, particularly concerning the association of ERR $\beta$ expression with survival of ovarian cancer patients, are sparse. In line with our data, a small mRNAbased study observed a tendency toward longer OS and PFS in ERR $\beta$ mRNA negative ovarian cancers (Sun et al. 2005).

In line with these observations, suggesting an oncogenic role of ERR $\beta$, we observed an elevated median receptor expression of ERR $\beta$ in ovarian cancers expressing high levels of HER 2 in our cohort. In contrast to these findings in ovarian cancers, two in vitro studies on breast or prostate cancer cells suggested a tumor-suppressive role of ERR $\beta$ (Madhu Krishna et al. 2018; Yu et al. 2008). In breast cancer, a direct interaction between ER $\alpha$ and ERR $\beta$ was observed by Tanida et al. (Tanida et al. 2015). Co-expression of ERR $\beta$ led to significantly reduced mobility of ligand-activated ER $\alpha$ and significantly repressed ER $\alpha$-mediated transcriptional activity (Tanida et al. 2015). In that study, ERR $\beta$ significantly inhibited E2-stimulated proliferation and expression of bcl-2 in MCF-7 breast cancer cells (Tanida et al. 2015). Moreover, ERR $\beta$ was reported to exhibit inhibitory effects on the cell cycle via regulation of p18, p21cip and cyclin D1 in breast cancer cells (Madhu Krishna et al. 2018). In line with these findings, we observed elevated expression of ERR $\beta$ in ovarian cancer expressing high levels of the tumor suppressor ER $\beta$.

Thus, these findings and our data suggest carefully balanced functions of ERR $\beta$ in ovarian cancer that can be affected by co-regulators. The observed negative effect on survival of ovarian cancer patients with tumors expressing ERR $\beta$ suggests that interaction with other influencers might mediate an oncogenic role in vivo. Future studies are strongly required to further elucidate the molecular mechanisms mediating the effect of ERR $\beta$ in ovarian cancer.

With regard to ERR $\gamma$, we found a highly significant association between high protein expression and shortened OS of patients with serous ovarian cancer in univariate as well as in multivariate survival analysis, suggesting a tumor-promoting role of this receptor in this cancer entity. In contrast to our data suggesting a significant association with shorter PFS, in a small mRNA-based study, it was reported that PFS of women with ERR $\gamma$ mRNA expressing ovarian cancers was significantly longer than in the ERR $\gamma$ negative group (Sun et al. 2005). However, the small number of cases in that study and the fact that mRNA levels do not reflect the amount of active protein have to be considered.

Moreover, we observed a significantly higher ERR $\gamma$ protein mean staining intensity in FIGO stages III and IV than in stages I and II. This is in line with previously published mRNA data, showing higher ERR $\gamma$ transcript levels in FIGO III and IV ovarian cancers (Sun et al. 2005).

The role of ERR $\gamma$ in ovarian cancer has not been investigated in detail. In an in vitro study on prostate cancer cells, ERR $\gamma$ was reported to exhibit anti-proliferative effects. (Yu et al. 2007). In contrast, in line with our data suggesting a tumor-promoting effect of ERR $\gamma$ protein in ovarian 
cancer, in a study on breast cancer cells, an oncogenic role of ERR $\gamma$ has been reported as exogenously transfected ERR $\gamma$ increased proliferation of MCF-7 cells (Ijichi et al. 2011). In endometrial cancer, estrogen-induced transcriptional activity of the ERE was repressed by ERR $\gamma$ in ER $\alpha$-positive cells but was stimulated by ERR $\gamma$ in ER $\alpha$-negative cells (Yamamoto et al. 2012). Moreover, a selective ERR $\gamma$ agonist, DY131, inhibited growth of ER $\alpha$-positive endometrial cancer cells but promoted that of the ER $\alpha$-negative cancer cells (Yamamoto et al. 2012), suggesting a subtle harmonized interaction between ER $\alpha$ and ERR $\gamma$ in the regulation of tumor cell proliferation, which is supported by our observation of a positive correlation between the expression of ERR $\gamma$ and ER $\alpha$. Consistent with this, Castet et al. showed that nuclear receptor interacting protein 140 (NRIP140), known to act as co-regulator of ER $\alpha$ and ERRs, differentially regulated ERR activity depending on the target sequence on the promoters (Castet et al. 2006). Regarding the E2-regulation of transcription through $\mathrm{ER} \alpha / \mathrm{Sp} 1$ interaction, target genes were involved in either positive or negative control of cell proliferation (Castet et al. 2006). Supporting the oncogenic role of ERR $\gamma$, we observed elevated expression levels of ERR $\gamma$ in ovarian cancers expressing high levels of CA125 and HER2.

Taken together, the data showing elevated ERR $\gamma$ mRNA levels in ovarian cancers, the significantly higher mean staining intensity of ERR $\gamma$ protein in higher staged tumors compared to those that were detected early as well as the association of high ERR $\gamma$ protein expression with shorter OS and PFS of ovarian cancer patients suggest a tumor-promoting role of ERR $\gamma$ in ovarian cancer.

As ERRs have been shown to be promising therapeutic targets in different cancer entities, several specific agonists and antagonists for ERR subtypes have been developed showing convincing effects in vitro (Ariazi and Jordan 2006; Du et al. 2017; Vernier et al. 2020).

\section{Conclusion}

In conclusion, we were able to detect considerable protein expression of ERR $\alpha, \beta$ and $\gamma$ in the vast majority of 208 ovarian cancer samples. Moreover, survival analyses showed a significant adverse effect of ERR $\beta$ and $\gamma$ protein expression on OS of serous ovarian cancer patients and pointed ERR $\gamma$ out to be an independent prognostic marker in this subgroup. This makes these ERRs interesting targets for therapeutic interventions using recently developed pharmacological ERR modulators. Future studies further elucidating mechanisms of action and function of the different ERR subtypes in ovarian cancer as well as in vivo approaches to test the applicability of ERR modulators in treatment of this cancer entity are necessary.
Supplementary Information The online version contains supplementary material available at https://doi.org/10.1007/s00432-021-03673-9.

Acknowledgements We thank Mrs. Bettina Federhofer for expert technical assistance.

Author contributions SST made substantial contributions to acquisition of data analysis and interpretation of data and drafting the manuscript. FW made substantial contributions to acquisition of data. MS made substantial contributions to acquisition of data. OO has been involved in revising the manuscript critically for important intellectual content. OT made substantial contributions to conception and design, acquisition of data analysis and interpretation of data and drafting the manuscript.

Funding Open Access funding enabled and organized by Projekt DEAL. The present study was supported by grant (Dz. St. 327/18) from the Medical University of Lublin, Poland.

Data availability Data available on request from the authors.

\section{Declarations}

Conflict of interest The authors declare that there is no conflict of interest that could be perceived as prejudicing the impartiality of the research reported.

Ethical approval The retrospective study was approved by the institutional review board "Ethics Committee University of Regensburg".

Consent for publication All authors read and approved the final manuscript.

Open Access This article is licensed under a Creative Commons Attribution 4.0 International License, which permits use, sharing, adaptation, distribution and reproduction in any medium or format, as long as you give appropriate credit to the original author(s) and the source, provide a link to the Creative Commons licence, and indicate if changes were made. The images or other third party material in this article are included in the article's Creative Commons licence, unless indicated otherwise in a credit line to the material. If material is not included in the article's Creative Commons licence and your intended use is not permitted by statutory regulation or exceeds the permitted use, you will need to obtain permission directly from the copyright holder. To view a copy of this licence, visit http://creativecommons.org/licenses/by/4.0/.

\section{References}

Abdul-Wahid A, Huang EH-B, Cydzik M, Bolewska-Pedyczak E, Gariépy J (2014) The carcinoembryonic antigen IgV-like N domain plays a critical role in the implantation of metastatic tumor cells. Mol Oncol 8:337-350. https://doi.org/10.1016/j.molonc. 2013.12.002

Abdul-Wahid A, Cydzik M, Fischer NW, Prodeus A, Shively JE, Martel A, Alminawi S, Ghorab Z, Berinstein NL, Gariépy J (2018) Serum-derived carcinoembryonic antigen (CEA) activates fibroblasts to induce a local re-modeling of the extracellular matrix that favors the engraftment of CEA-expressing tumor cells. Int $\mathbf{J}$ Cancer 143:1963-1977. https://doi.org/10.1002/ijc.31586 
Ariazi EA, Jordan VC (2006) Estrogen-related receptors as emerging targets in cancer and metabolic disorders. Curr Top Med Chem 6:203-215. https://doi.org/10.2174/1568026610606030203

Ariazi EA, Clark GM, Mertz JE (2002) Estrogen-related receptor alpha and estrogen-related receptor gamma associate with unfavorable and favorable biomarkers, respectively, in human breast cancer. Cancer Res 62:6510-6518

Castet A, Herledan A, Bonnet S, Jalaguier S, Vanacker J-M, Cavaillès V (2006) Receptor-interacting protein 140 differentially regulates estrogen receptor-related receptor transactivation depending on target genes. Mol Endocrinol 20:1035-1047. https://doi.org/10. 1210/me.2005-0227

Chan KKL, Siu MKY, Jiang Y-X, Wang J-J, Wang Y, Leung THY, Liu SS, Cheung ANY, Ngan HYS (2017) Differential expression of estrogen receptor subtypes and variants in ovarian cancer: effects on cell invasion, proliferation and prognosis. BMC Cancer 17:606. https://doi.org/10.1186/s12885-017-3601-1

Charafe-Jauffret E, Tarpin C, Bardou V-J, Bertucci F, Ginestier C, Braud A-C, Puig B, Geneix J, Hassoun J, Birnbaum D, Jacquemier J, Viens P (2004) Immunophenotypic analysis of inflammatory breast cancers: identification of an 'inflammatory signature.' J Pathol 202:265-273. https://doi.org/10.1002/path.1515

Chen Y-C, Lee T-H, Tzeng S-L (2019) Reduced DAXX expression is associated with reduced CD24 expression in colorectal cancer. Cells. https://doi.org/10.3390/cells8101242

Du Y, Song L, Zhang L, Ling H, Zhang Y, Chen H, Qi H, Shi X, Li Q (2017) The discovery of novel, potent ERR-alpha inverse agonists for the treatment of triple negative breast cancer. Eur J Med Chem 136:457-467. https://doi.org/10.1016/j.ejmech. 2017.04.050

Dwyer MA, Joseph JD, Wade HE, Eaton ML, Kunder RS, Kazmin D, Chang C, McDonnell DP (2010) WNT11 expression is induced by estrogen-related receptor alpha and beta-catenin and acts in an autocrine manner to increase cancer cell migration. Cancer Res 70:9298-9308. https://doi.org/10.1158/0008-5472.CAN-10-0226

Fujimoto J, Alam SM, Jahan I, Sato E, Sakaguchi H, Tamaya T (2007) Clinical implication of estrogen-related receptor (ERR) expression in ovarian cancers. J Steroid Biochem Mol Biol 104:301-304. https://doi.org/10.1016/j.jsbmb.2007.03.016

Halon A, Nowak-Markwitz E, Maciejczyk A, Pudelko M, Gansukh T, Györffy B, Donizy P, Murawa D, Matkowski R, Spaczynski M, Lage H, Surowiak P (2011) Loss of estrogen receptor beta expression correlates with shorter overall survival and lack of clinical response to chemotherapy in ovarian cancer patients. Anticancer Res 31:711-718

Ijichi N, Shigekawa T, Ikeda K, Horie-Inoue K, Fujimura T, Tsuda H, Osaki A, Saeki T, Inoue S (2011) Estrogen-related receptor $\gamma$ modulates cell proliferation and estrogen signaling in breast cancer. J Steroid Biochem Mol Biol 123:1-7. https://doi.org/10. 1016/j.jsbmb.2010.09.002

Kraus RJ, Ariazi EA, Farrell ML, Mertz JE (2002) Estrogen-related receptor alpha 1 actively antagonizes estrogen receptor-regulated transcription in MCF-7 mammary cells. J Biol Chem 277:2482624834. https://doi.org/10.1074/jbc.M202952200

Lam SS, Mak AS, Yam JW, Cheung AN, Ngan HY, Wong AS (2014) Targeting estrogen-related receptor alpha inhibits epithelial-tomesenchymal transition and stem cell properties of ovarian cancer cells. Mol Ther 22:743-751. https://doi.org/10.1038/mt.2014.1

Liu G, Sun P, Dong B, Sehouli J (2018) Key regulator of cellular metabolism, estrogen-related receptor $\alpha$, a new therapeutic target in endocrine-related gynecological tumor. Cancer Manag Res 10:6887-6895. https://doi.org/10.2147/CMAR.S182466

Madhu Krishna B, Chaudhary S, Mishra DR, Naik SK, Suklabaidya S, Adhya AK, Mishra SK (2018) Estrogen receptor $\alpha$ dependent regulation of estrogen related receptor $\beta$ and its role in cell cycle in breast cancer. BMC Cancer 18:607. https://doi.org/10.1186/ s12885-018-4528-x

May FE (2014) Novel drugs that target the estrogen-related receptor alpha: their therapeutic potential in breast cancer. Cancer Manag Res 6:225-252. https://doi.org/10.2147/CMAR.S35024

Mirlacher M, Simon R (2010) Recipient block TMA technique. Methods Mol Biol 664:37-44. https://doi.org/10.1007/ 978-1-60761-806-5_4

O'Donnell AJM, Macleod KG, Burns DJ, Smyth JF, Langdon SP (2005) Estrogen receptor-alpha mediates gene expression changes and growth response in ovarian cancer cells exposed to estrogen. Endocr Relat Cancer 12:851-866. https://doi.org/10.1677/erc.1. 01039

Ranhotra HS (2012) The estrogen-related receptors: orphans orchestrating myriad functions. J Recept Signal Transduct Res 32:47-56. https://doi.org/10.3109/10799893.2011.647350

Remmele W, Stegner HE (1987) Vorschlag zur einheitlichen Definition eines Immunreaktiven Score (IRS) für den immunhistochemischen Ostrogenrezeptor-Nachweis (ER-ICA) im Mammakarzinomgewebe (Recommendation for uniform definition of an immunoreactive score (IRS) for immunohistochemical estrogen receptor detection (ER-ICA) in breast cancer tissue). Pathologe 8:138-140

Saeland E, Belo AI, Mongera S, van Die I, Meijer GA, van Kooyk Y (2012) Differential glycosylation of MUC1 and CEACAM5 between normal mucosa and tumour tissue of colon cancer patients. Int J Cancer 131:117-128. https://doi.org/10.1002/ijc. 26354

Schüler-Toprak S, Moehle C, Skrzypczak M, Ortmann O, Treeck O (2017) Effect of estrogen receptor $\beta$ agonists on proliferation and gene expression of ovarian cancer cells. BMC Cancer 17:319. https://doi.org/10.1186/s12885-017-3246-0

Siegel RL, Miller KD, Jemal A (2018) Cancer statistics, 2018. CA Cancer J Clin 68:7-30. https://doi.org/10.3322/caac.21442

Spaulding DC, Spaulding BO (2002) Epidermal growth factor receptor expression and measurement in solid tumors. Semin Oncol 29:45-54. https://doi.org/10.1053/sonc.2002.35647

Stein RA, McDonnell DP (2006) Estrogen-related receptor alpha as a therapeutic target in cancer. Endocr Relat Cancer 13(Suppl 1):S25-32. https://doi.org/10.1677/erc.1.01292

Sun P, Sehouli J, Denkert C, Mustea A, Könsgen D, Koch I, Wei L, Lichtenegger W (2005) Expression of estrogen receptor-related receptors, a subfamily of orphan nuclear receptors, as new tumor biomarkers in ovarian cancer cells. J Mol Med 83:457-467. https://doi.org/10.1007/s00109-005-0639-3

Tanida T, Matsuda KI, Yamada S, Hashimoto T, Kawata M (2015) Estrogen-related receptor $\beta$ reduces the subnuclear mobility of estrogen receptor $\alpha$ and suppresses estrogen-dependent cellular function. J Biol Chem 290:12332-12345. https://doi.org/10.1074/ jbc.M114.619098

Tohmé M, Prud'homme SM, Boulahtouf A, Samarut E, Brunet F, Bernard L, Bourguet W, Gibert Y, Balaguer P, Laudet V (2014) Estrogen-related receptor $\gamma$ is an in vivo receptor of bisphenol A. FASEB J 28:3124-3133. https://doi.org/10.1096/fj.13-240465

Torre LA, Trabert B, DeSantis CE, Miller KD, Samimi G, Runowicz CD, Gaudet MM, Jemal A, Siegel RL (2018) Ovarian cancer statistics, 2018. CA Cancer J Clin 68:284-296. https://doi.org/10. 3322/caac. 21456

Treeck O, Pfeiler G, Mitter D, Lattrich C, Piendl G, Ortmann O (2007) Estrogen receptor \{beta 1 exerts antitumoral effects on SK-OV-3 ovarian cancer cells. J Endocrinol 193:421-433. https://doi.org/ 10.1677/JOE-07-0087

Uysal-Onganer P, Kawano Y, Caro M, Walker MM, Diez S, Darrington RS, Waxman J, Kypta RM (2010) Wnt-11 promotes neuroendocrine-like differentiation, survival and migration of prostate cancer cells. Mol Cancer 9:55. https://doi.org/10.1186/1476-4598-9-55 
Vernier M, Dufour CR, McGuirk S, Scholtes C, Li X, Bourmeau G, Kuasne H, Park M, St-Pierre J, Audet-Walsh E, Giguère V (2020) Estrogen-related receptors are targetable ROS sensors. Genes Dev 34:544-559. https://doi.org/10.1101/gad.330746.119

Wang C-W, Hsu W-H, Tai C-J (2017) Antimetastatic effects of cordycepin mediated by the inhibition of mitochondrial activity and estrogen-related receptor $\alpha$ in human ovarian carcinoma cells. Oncotarget 8:3049-3058. https://doi.org/10.18632/oncot arget. 13829

Yamamoto T, Mori T, Sawada M, Kuroboshi H, Tatsumi H, Yoshioka T, Matsushima H, Iwasaku K, Kitawaki J (2012) Estrogen-related receptor- $\gamma$ regulates estrogen receptor- $\alpha$ responsiveness in uterine endometrial cancer. Int J Gynecol Cancer 22:1509-1516. https:// doi.org/10.1097/IGC.0b013e31826fd623

Yu S, Wang X, Ng C-F, Chen S, Chan FL (2007) ERRgamma suppresses cell proliferation and tumor growth of androgen-sensitive and androgen-insensitive prostate cancer cells and its implication as a therapeutic target for prostate cancer. Cancer Res 67:49044914. https://doi.org/10.1158/0008-5472.CAN-06-3855
Yu S, Wong YC, Wang XH, Ling MT, Ng CF, Chen S, Chan FL (2008) Orphan nuclear receptor estrogen-related receptor-beta suppresses in vitro and in vivo growth of prostate cancer cells via p21(WAF1/ CIP1) induction and as a potential therapeutic target in prostate cancer. Oncogene 27:3313-3328. https://doi.org/10.1038/sj.onc. 1210986

Zhao Y, Li Y, Lou G, Zhao L, Xu Z, Zhang Y, He F (2012) MiR-137 targets estrogen-related receptor alpha and impairs the proliferative and migratory capacity of breast cancer cells. PLoS ONE 7:e39102. https://doi.org/10.1371/journal.pone.0039102

Publisher's Note Springer Nature remains neutral with regard to jurisdictional claims in published maps and institutional affiliations. 